\title{
A Survey of the Regulatory Requirements for the Waiver of In Vivo Bioequivalence Studies of Generic Products in Certain Dosage Forms by Participating Regulators and Organisations of the International Pharmaceutical Regulators Programme
}

\begin{abstract}
Alfredo García-Arieta ${ }^{1}$, Craig Simon ${ }^{2}$, Andrew Tam $^{2}$, Gustavo Mendes Lima Santos ${ }^{3}$, Eduardo Agostinho Freitas Fernandes $^{3}$, Zulema Rodríguez Martínez ${ }^{4}$, Clare Rodrigues ${ }^{5}$, Sang Aeh Park ${ }^{6}$, JaYoung Kim ${ }^{6}$, Kwansoo Kim ${ }^{6}$, Ryosuke Kuribayashi $^{7}$, Aya Myoenzono ${ }^{7}$, Kohei Shimojo ${ }^{7}$, Chantal Walther ${ }^{8}$, Matthias S. Roost ${ }^{8}$, Wen-Yi Hung ${ }^{9}$, Li-feng Hsu ${ }^{10}$, Christopher Crane ${ }^{11}$, April C. Braddy ${ }^{12}$, Joy van Oudtshoorn ${ }^{13}$, Diego Alejandro Gutierrez Triana ${ }^{14}$, Erwin Guzmán Aurela $^{14}$, Ben Jones ${ }^{15}$, Henrike Potthast ${ }^{16}$, Ivana Abalos ${ }^{17}$

${ }^{1}$ World Health Organisation (WHO) Prequalification of Medicines Programme and Agencia Española de Medicamentos y Productos Sanitarios (AEMPS), Madrid, Spain; ${ }^{2}$ Health Canada, Ottawa ON, Canada; ${ }^{3}$ Agência Nacional de Vigilância Sanitária (ANVISA), Brasília, Brazil; ${ }^{4}$ Comisión Federal para la Protección contra Riesgos Sanitarios (COFEPRIS), Ciudad de México, México; ${ }^{5}$ Health Sciences Authority (HSA), Health Products Regulation Group, Medicinal Products Pre-Marketing Cluster, Therapeutic Products Branch, Singapore; ${ }^{6}$ Ministry of Food and Drug Safety (MFDS), Osongeup Heungdeok-gu, Cheongju-si, Chungcheongbuk-do, Republic of Korea; ${ }^{7}$ Pharmaceuticals and Medical Devices Agency (PMDA), Tokyo, Japan; ${ }^{8}$ Swissmedic, Schweizerisches Heilmittelinstitut, Bern, Switzerland; ${ }^{9}$ Taiwan Food and Drug Administration (TFDA), Nangang, Taipei, Taiwan, R.O.C.; ${ }^{10}$ Center for Drug Evaluation (CDE), Taipei, Taiwan R.O.C.; ${ }^{11}$ Therapeutic Goods Administration (TGA), Australia; ${ }^{12}$ U.S. Department of Health and Human Services, Food and Drug Administration (U.S. FDA), Center for Drug Evaluation and Research, Office of Generic Drugs, Silver Spring, MD; ${ }^{13}$ South African Health Products Regulatory Authority (SAHPRA), Arcadia, Pretoria, South Africa; ${ }^{14}$ Instituto Nacional de Vigilancia de Medicamentos y Alimentos (INVIMA), Bogotá. Colombia; ${ }^{15}$ New Zealand Medicines and Medical Devices Safety Authority (Medsafe), Ministry of Health, Wellington, New Zealand; ${ }^{16}$ European Medicines Agency, Orlyplein 24, 1043 DP Amsterdam, The Netherlands and Federal Institute for Drugs and Medical Devices (BfArM), Bonn, Germany; ${ }^{17}$ Administración Nacional de Medicamentos, Alimentos y Tecnología Médica (ANMAT), Ciudad Autónoma de Buenos Aires, Argentina
\end{abstract}

Corresponding author: Alfredo García-Arieta, División de Farmacología y Evaluación Clínica. Subdirección General de Medicamentos de Uso Humano. Agencia Española de Medicamentos y Productos Sanitarios, C/ Campezo 1. Edificio 8, Planta 2 Oeste E-28022 Madrid, Spain; TEL: 34918225167; Fax: 34918225161; email: agarciaa@aemps.es

Received, January 27, 2021; Accepted, March 10, 2021; Published, March 14, 2021

\begin{abstract}
The requirements to waive in vivo bioequivalence studies for immediate release solid oral dosage forms based on the Biopharmaceutics Classifications System (BCS) are well known, and biowaivers ${ }^{\mathrm{a}}$ for other types of oral dosage forms based on pre-defined criteria may also be acceptable. Similarly, biowaivers for dosage forms such as injectable products may also be allowed if certain criteria are met. The current paper summarises the biowaiver requirements for oral solutions and suspensions, soft gelatin capsules and injectable products (intravenous injections, subcutaneous and intramuscular injections, emulsions for injection and micellar solutions for injection) among the participants of the Bioequivalence Working Group for Generics (BEWGG) of the International Pharmaceutical Regulators Programme (IPRP). A review of the requirements indicated that there was a trend towards convergence when the dosage form became less complex; however, the most common approach used by each of the jurisdictions was a case-by-case approach given that most jurisdictions do not have well defined guidelines to support all possible scenarios. Even in the simplest case of intravenous solutions, the acceptability of qualitative changes in excipients differ between the IPRP members. Notwithstanding the differences, the dissemination of the information is a first step towards regulatory convergence regarding biowaivers for certain dosage forms and should be useful for pharmaceutical companies currently developing generic medicinal products for IPRP jurisdictions.
\end{abstract}

\section{INTRODUCTION}

Medicines regulatory authorities aim to address rising health care costs and promote access to medicines worldwide through review and approval of quality generic products that are interchangeable with the corresponding reference medicinal product.

\footnotetext{
a For the U.S. FDA, the term "biowaiver" refers to either the decision to waive an in vivo bioequivalence requirement under $21 \mathrm{CFR}$ 320.22 or the decision to accept in vitro bioequivalence data in accordance with 21 CFR 320.24(a).
} 
The International Generic Drug Regulators Programme (IGDRP) was created to promote collaboration and convergence among generic drug regulators in order to address the challenges posed by increasing workloads, globalisation and complexity of scientific issues. In 2018 the IGDRP merged with the International Pharmaceutical Regulators Forum (IPRF) to form the International Pharmaceutical Regulators Programme (IPRP), which allows its members to exchange information on issues of mutual interest, promote cooperation, maximise synergies and avoid duplication of effort, create a regulatory hub for pharmaceutical manufacturers of all medicinal products and enable linkages with other initiatives to simplify the numerous forms of international regulatory collaboration (1).

The Bioequivalence Working Group for Generics (BEWGG), in particular, aims to promote greater collaboration, regulatory convergence and potential mutual reliance on respective bioequivalence assessments in the longer term. This group is composed of the following 15 regulators/organisations: Administración Nacional de Medicamentos, Alimentos y Tecnología Médica (ANMAT, Argentina), Agência Nacional de Vigilância Sanitária (ANVISA, Brazil), Federal Commission for the Protection against Sanitary Risks (COFEPRIS, Mexico), European Commission / European Medicines Agency (EC/EMA, EU), Health Canada (HC), the Health Sciences Authority (HSA, Singapore), Instituto Nacional de Vigilancia de Medicamentos y Alimentos (INVIMA, Colombia), South African Health Products Regulatory Authority (SAHPRA), Medsafe (New Zealand), the Ministry of Food and Drug Safety (MFDS, Republic of Korea), the Pharmaceuticals and Medical Devices Agency (PMDA, Japan), Swissmedic (Switzerland), the Taiwan Food and Drug Administration (TFDA), Therapeutic Goods Administration (TGA, Australia) and the United States Food and Drug Administration (U.S. FDA), as well as one observer from the World Health Organization (WHO).

The requirements to waive in vivo bioequivalence studies for immediate release (IR) solid oral dosage forms based on the Biopharmaceutics Classification System (i.e., BCS biowaivers) in IPRP jurisdictions have been previously described (2) and are now harmonised by the International Council for Harmonisation of Technical Requirements for Pharmaceuticals for Human Use (ICH) (3). In addition, waivers of in vivo bioequivalence studies may be applied to additional strengths of IR solid oral dosage forms with respect to the strength for which in vivo bioequivalence has been shown (4). Furthermore, waivers of in vivo bioequivalence studies may also apply to certain dosage forms irrespective of the BCS waiver criteria. For example, in vivo bioequivalence studies may be waived for some orally administered and systemically-acting dosage forms (e.g., oral solutions, oral suspensions and soft gelatin capsules), non-oral systemically acting dosage forms (e.g., intravenous injections, subcutaneous and intramuscular injections, emulsions for injection and micellar solutions for injection) and locally-acting dosage forms (e.g., otic and ophthalmic solutions, cutaneous/topical products, vaginal pessaries, enemas, nasal and orally inhaled products for pulmonary action). In such cases, waivers of in vivo bioequivalence studies could be based on in vitro data alone.

For the purpose of this paper, in vivo bioequivalence investigations refer not only to pharmacokinetic studies, but also to therapeutic equivalence studies with pharmacodynamic or clinical endpoints, although in some jurisdictions the term "bioequivalence studies" refers only to pharmacokinetic studies.

The objective of this paper is to summarise the requirements to waive the in vivo demonstration of bioequivalence for the abovementioned oral and injectable dosage forms among the regulators and organisations that participate actively in the IPRP BEWGG. The waiver requirements for the remaining dosage forms will be summarised in separate papers. The sharing of this information is a first step towards regulatory convergence in this area.

\section{MATERIALS AND METHODS}

The IPRP BEWGG conducted a survey of the requirements to demonstrate bioequivalence in different types of immediate release oral and injectable dosage forms: oral solutions, oral suspensions, soft gelatin capsules, intravenous injections, subcutaneous and intramuscular injections, emulsions for injection, micellar solutions for injection and powders for reconstitution.

This information was obtained from the participating regulatory authorities and organisations in the BEWGG and is based on their respective regulatory guidance documents and policies (5-23).

\section{RESULTS}

Oral products

Oral solutions. In vivo bioequivalence studies for 
oral solutions can be waived in all jurisdictions except Japan (Table 1), where waivers for aqueous solutions are not accepted and current Japanese guidelines do not contain information regarding waivers for oral solutions. In the case of oily solutions, the situation is more diverse. Based on current regulations, Taiwan and the USA would accept a waiver for oily oral solutions as they do not differentiate oily solutions from other solutions; however, waiver requirements for oily solutions are not described in current guidance documents from Argentina, Australia, Canada, Colombia, the European Union (EU), New Zealand, Mexico, Singapore, South Africa, Switzerland and the WHO. Regardless, these members have indicated that they would consider the acceptability of a waiver based on the physicochemical properties of the dosage form. For example, Argentina, Australia, Canada, the EU, New Zealand, South Africa and Switzerland would require that the type of oil used in the vehicle for the proposed generic be the same as that in the reference product. On the contrary, Brazil and the Republic of Korea would not accept waivers for oily solutions.

For other types of oral solutions, a waiver from conducting in vivo bioequivalence studies would be considered acceptable based on the qualitative and quantitative differences in the nonmedicinal ingredients / excipients in the formulation of the test product when compared to the reference product. Qualitative differences in excipients are acceptable in principle if the excipients are not considered to be critical (i.e., known not to affect the bioavailability of the active ingredient(s)). For example, qualitative and quantitative modifications in preservatives, viscosity agents, $\mathrm{pH}$ buffers, colorants, flavors, some sweeteners) could be permitted whereas qualitative similarity and remarkably close quantitative similarity would be expected for excipients that enhance absorption (e.g., polysorbate 80). In 2016, the EU published an online questions and answers (Q\&A) document clarifying that the similarity of excipients in oral solutions should be assessed according to the requirements for BCS-based biowaivers (24). Colombia (12), Mexico and the WHO (20) also provided similar recommendations. The principles used by Colombia, the EU, Mexico and the WHO are also applied in Australia, Canada, New Zealand and Switzerland, where non-critical excipients can be modified for oral solutions containing BCS class I drugs, but not for oral solutions containing BCS class II, III and IV drugs where the excipients must be qualitatively the same and quantitatively similar. For example, the substitution of a co- solvent for another co-solvent cannot be justified by in vitro data showing a similar solubilising capacity of the new formulation/excipient mixture; as a result, an in vivo bioequivalence study would be required. While recommended criteria are described in Health Canada guidance documents, any difference beyond the described criteria should be scientifically justified and the potential impact on the safety and efficacy of the drug product should be discussed (6). Similarly, in the USA, the different amount of any excipient should be within US FDA inactive ingredients database limits and the new amounts should not be associated with safety or efficacy concerns (25).

For excipients that are considered critical because they are known to potentially affect the bioavailability of active ingredients by altering the gastrointestinal transit, permeability or stability of the active ingredients, Australia, Brazil, Canada, Colombia, the EU, New Zealand, the Republic of Korea, South Africa, Singapore, Switzerland, Taiwan and the WHO do not allow qualitatively changes, but permit minor quantitative changes in the formulation of the generic product when compared to the reference product. In the case of the USA and Argentina, critical excipients can be changed qualitatively and quantitatively within certain justified limits (25). The list of critical excipients is not exhaustive but includes surfactants (e.g., SLS, castor oil ethoxylate, polysorbate 80), sweeteners (e.g., sorbitol and mannitol), excipients that affect transporters (e.g., PEG-400), co-solvents and complexing agents (e.g., cyclodextrins). Each jurisdiction may have different criteria on the types of excipients that are considered critical and the quantitative differences allowed. For example, there are no defined criteria, or it is considered case-by-case in Argentina, Australia, Brazil, Colombia, the EU, New Zealand, Republic of Korea, Singapore, Switzerland, Taiwan and the USA. A relative change of $10 \%$ with respect to the absolute amount in the reference is allowed in Canada, and a level 1 difference, as described in the US FDA SUPAC-IR guideline (26), is allowed by South Africa and the WHO.

In the case of powders for reconstitution of oral solutions, the same requirements apply because the product is an oral solution at the time of administration. Japan has not described this possibility in the guidelines, and a waiver is not acceptable in principle. In Canada and the USA, the requirements for a waiver for powders for oral solution are not specifically described in their respective guidelines but a waiver may be possible based on physicochemical properties of the formulation. 
Oral suspensions. South Africa will consider waivers for oral suspensions for systemic action if they have the same qualitative composition and comparable physicochemical properties for parameters such as crystallographic structure, particle size distribution and in vitro dissolution profiles. Australia and Singapore have no specific guidance but will consider an application based on the test and reference products having identical quantitative formulations and the physicochemical equivalence of justified parameters (e.g., polymorphic form, particle size distribution, viscosity, $\mathrm{pH}$ and dissolution profiles across the $\mathrm{pH}$ range 1.2 to 6.8 ). In all other jurisdictions in vivo bioequivalence studies are required.

In the case of locally acting suspensions, waivers can be accepted in Brazil and Singapore, and considered on a case-by-case basis in Argentina, Australia, Canada, Colombia, and the EU (27), New Zealand, the Republic of Korea, Switzerland and Taiwan if the drug substance is not systemically absorbed. In addition, in the USA, specific examples where a waiver is accepted are sevelamer (28-30), colesevelam $(31,32)$ and cholestyramine (33). It should be noted that the above recommendations for the USA may be based primarily on the locally acting nature of the drug and not specifically the dosage form. For South Africa and the WHO, the requirements for waivers for locally acting suspensions are not described in the current guideline (20), but existing guidelines from Stringent Regulatory Authorities may be considered. Presently, Japan and Mexico do not accept waivers for locally acting suspensions.

In the case of powders for reconstitution of oral suspensions the same requirements apply because the product is an oral suspension at the time of administration.

Soft Gelatin Capsules. With the exception of Brazil, Canada, Japan and the Republic of Korea, a waiver from conducting in vivo bioequivalence studies could be acceptable in the remaining jurisdictions. Although soft gelatin capsules are solid oral dosage forms and the possibility of a waiver is not included in the guidance of these jurisdictions, it may be possible to consider a biowaiver if the drug substance is in solution inside the capsule and the gelatin coating is fastdissolving (e.g., products containing Omega-3-acid ethyl esters). For example, a waiver from conducting in vivo bioequivalence studies could be accepted for products containing omega-3-acid ethyl esters in the USA (34); however, in most cases in vivo studies are required to demonstrate bioequivalence (e.g., products containing progesterone (35)). Similar to the biowaiver requirements for aqueous and oily oral solutions, the acceptability of a biowaiver for a soft gelatin capsule would be considered acceptable for Australia, the EU (36), New Zealand, Singapore and Switzerland if the fill liquid is qualitatively the same and quantitatively similar to that of the comparator product. Argentina, Colombia, Mexico, South Africa, Taiwan and the WHO Prequalification Programme (WHO PQT-m) would consider a biowaiver if the excipients of the test product are qualitatively and quantitatively identical to the reference product).

\section{Injectable products}

Intravenous injections. In vivo bioequivalence studies for simple intravenous solutions for injection or infusion may be waived in all jurisdictions (Table 2). For Canada, the formulations of the generic product and the reference product should be qualitatively the same and quantitatively essentially the same (excipient variation between products is within $\pm 10 \%$ unless data is available to support a wider variation) (7). Any differences beyond the criteria should be scientifically justified. Only preservatives, buffers, antioxidants can be different in the Republic of Korea and the USA, while isotonic agents can also be changed in Australia, Canada, Colombia, the EU, Japan, New Zealand, Singapore, South Africa, Switzerland, Taiwan and WHO. Furthermore, Australia no longer approves new sterile single use injection products with preservatives that have no other function given that there is no use for the preservative; as a result, Australia will allow waivers for single use injections for a generic without a preservative even though a reference may contain a preservative. In the EU and Switzerland, change in the type of cyclodextrin has been accepted based on in vitro data for voriconazole because it was justified that it does not affect the in vivo release of the drug substance. In Canada, change in the type of cyclodextrin was supported by in vitro data as well as a clinical justification. Excipients that may affect disposition and/or safety (e.g., surfactants like Cremophor) should not differ in Australia, Colombia, the EU, New Zealand, Singapore, Switzerland and WHO while Argentina, Canada and Japan would assess the acceptability of the waiver on a case-by-case basis. In South Africa and Taiwan, the criteria have not been defined for changes to the mentioned excipients. For Brazil, any excipient can be changed as long as the new excipients are well established for intravenous administration and used in suitable concentrations, but any differences in preservatives, buffers and thickening agents need to be justified. 
Table 1. Comparison of Biowaiver Requirements for Certain Oral Dosage Forms Among IPRP BEWGG Participants

\begin{tabular}{|c|c|c|c|c|c|c|c|c|c|c|c|c|c|c|c|c|}
\hline & 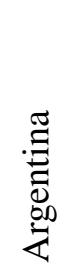 & 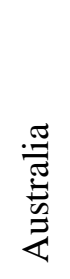 & 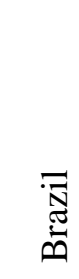 & $\begin{array}{l}\widetilde{\Xi} \\
\widetilde{\Xi} \\
\widetilde{\Xi}\end{array}$ & $\frac{\frac{\pi}{0}}{\frac{0}{0}}$ & 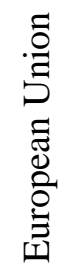 & $\begin{array}{l}\text { స్ } \\
\text { స్心 }\end{array}$ & $\begin{array}{l}\stackrel{0}{x} \\
\sum_{\Sigma}^{0}\end{array}$ & 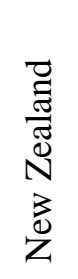 & 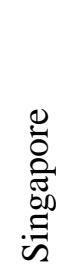 & 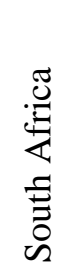 & 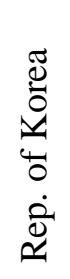 & 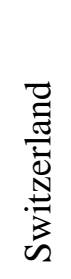 & 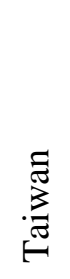 & $\tilde{\Omega}$ & $\stackrel{0}{\underset{1}{3}}$ \\
\hline \multicolumn{17}{|l|}{ Oral solutions } \\
\hline \multicolumn{17}{|l|}{ Aqueous Solutions } \\
\hline Consider waivers & $\mathbf{Y}$ & $\mathbf{Y}$ & $\mathbf{Y}$ & $\mathbf{Y}$ & $\mathbf{Y}$ & $\mathbf{Y}$ & $\mathbf{N}^{\mathbf{a}}$ & $\mathbf{Y}^{\mathbf{a}}$ & $\mathbf{Y}$ & $\mathbf{Y}$ & $\mathbf{Y}$ & $\mathbf{Y}$ & $\mathbf{Y}$ & $\mathbf{Y}$ & $\mathbf{Y}$ & $\mathbf{Y}$ \\
\hline \multicolumn{17}{|l|}{ Oily Solutions } \\
\hline Consider waivers & $\mathbf{C}^{\mathrm{a}}$ & - & - & - & - & - & $\mathbf{N}$ & $\mathbf{Y}^{\mathbf{a}}$ & - & $\mathbf{Y}$ & - & $\mathbf{N}$ & - & $\mathbf{Y}$ & - & - \\
\hline $\begin{array}{l}\text { May consider waivers with the } \\
\text { same oil vehicle }\end{array}$ & $\mathbf{Y}$ & $\mathbf{Y}$ & $\mathbf{N}$ & $\mathbf{Y}$ & $\mathbf{Y}$ & $\mathbf{Y}$ & $\mathbf{N}$ & $\mathbf{Y}^{\mathrm{a}}$ & $\mathbf{Y}$ & $\mathbf{Y}$ & $\mathbf{Y}$ & $\mathbf{N}$ & $\mathbf{Y}$ & $\mathbf{Y}$ & $\mathbf{Y}$ & $\mathbf{Y}$ \\
\hline $\begin{array}{l}\text { May consider waivers with } \\
\text { different oil vehicle }\end{array}$ & $\mathbf{N}$ & $\mathbf{N}$ & $\mathbf{N}$ & $\mathbf{N}$ & - & $\mathbf{N}$ & $\mathbf{N}$ & $\mathbf{N}^{\mathrm{a}}$ & $\mathbf{N}$ & $\mathbf{Y}$ & $\mathbf{N}$ & $\mathbf{N}$ & $\mathbf{C}$ & $\mathbf{Y}$ & $\mathbf{C}$ & $\mathbf{N}$ \\
\hline \multicolumn{17}{|l|}{ Similarity in Excipient Composition } \\
\hline $\begin{array}{l}\text { Consider qualitative changes in excipients that are } \\
\text { known not to affect BA, e.g., preservatives, etc. }\end{array}$ & $\mathbf{Y}$ & $\mathbf{Y}$ & $\mathbf{Y}$ & $\mathbf{Y}$ & $\mathbf{Y}$ & $\mathbf{Y}$ & N/A & $\mathbf{Y}$ & $\mathbf{Y}$ & $\mathbf{Y}$ & $\mathbf{Y}$ & $\mathbf{Y}$ & $\mathbf{Y}$ & $\mathbf{Y}$ & $\mathbf{Y}$ & $\mathbf{Y}$ \\
\hline $\begin{array}{l}\text { Consider qualitative changes in other non-critical } \\
\text { excipients for BCS class II, III and IV drugs }\end{array}$ & $\mathbf{Y}$ & $\mathbf{N}$ & $\mathbf{N}$ & $\mathbf{N}$ & $\mathbf{N}$ & $\mathbf{N}$ & N/A & $\mathbf{Y}^{\mathbf{a}}$ & $\mathbf{N}$ & $\mathbf{Y}$ & $\mathbf{Y}$ & $\mathbf{Y}$ & $\mathbf{N}$ & $\mathbf{Y}$ & $\mathbf{Y}$ & $\mathbf{N}$ \\
\hline Can critical excipients be changed quantitatively? & $\mathbf{C}$ & $\mathbf{C}$ & $\mathbf{C}$ & $\mathbf{Y}^{\mathbf{b}}$ & $\mathbf{C}$ & $\mathbf{C}$ & N/A & $\mathbf{C}$ & $\mathbf{C}$ & $\mathbf{C}$ & $\mathbf{Y}^{\mathbf{b}}$ & $\mathbf{N}$ & $\mathbf{C}$ & $\mathbf{C}$ & $\mathbf{Y}^{\mathbf{b}}$ & $\mathbf{Y}^{\mathbf{b}}$ \\
\hline \multicolumn{17}{|l|}{ Oral suspensions } \\
\hline Consider waivers for systemically acting products & $\mathbf{N}$ & $\mathbf{Y}^{\mathbf{c}}$ & $\mathbf{N}$ & $\mathbf{N}$ & $\mathbf{N}$ & $\mathbf{N}$ & $\mathbf{N}$ & $\mathbf{N}^{\mathrm{a}}$ & $\mathbf{N}$ & $\mathbf{Y}^{\mathbf{c}}$ & $\mathbf{Y}$ & $\mathbf{N}$ & $\mathbf{N}$ & $\mathbf{N}$ & $\mathbf{N}$ & $\mathbf{N}$ \\
\hline Consider waivers for locally acting products & $\mathbf{C}$ & $\mathbf{C}$ & $\mathbf{Y}$ & $\mathbf{C}$ & $\mathbf{C}$ & $\mathbf{C}$ & $\mathbf{N}$ & $\mathbf{N}^{\mathbf{a}}$ & $\mathbf{C}$ & $\mathbf{Y}$ & $\mathbf{C}$ & $\mathbf{C}$ & $\mathbf{C}$ & $\mathbf{C}$ & $\mathbf{C}^{\mathrm{e}}$ & $\mathbf{C}$ \\
\hline \multicolumn{17}{|l|}{ Soft Gelatin Capsules } \\
\hline May consider waivers & $\mathbf{Y}^{\mathrm{c}, \mathrm{d}}$ & $\mathbf{Y}^{\mathbf{a}}$ & $\mathbf{N}$ & $\mathbf{N}$ & $\mathbf{Y}^{\mathbf{d}}$ & $\mathbf{Y}^{\mathbf{a}}$ & $\mathbf{N}$ & $\mathbf{Y}^{\mathbf{c}}$ & $\mathbf{Y}^{\mathbf{a}}$ & $\mathbf{Y}^{\mathrm{a}}$ & $\mathbf{Y}^{\mathbf{d}}$ & $\mathbf{N}$ & $\mathbf{Y}^{\mathrm{a}}$ & $\mathbf{Y}^{\mathbf{d}}$ & $\mathbf{N}$ & $\mathbf{Y}^{\mathrm{d}}$ \\
\hline
\end{tabular}

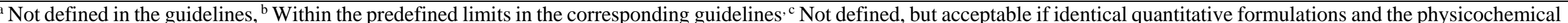

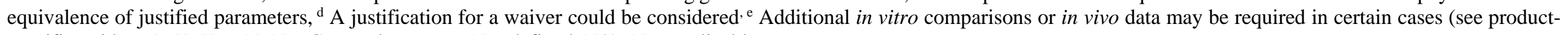
specific guidance). Y: Yes; N: No; C: case-by-case, -: Not defined, N/A: Not applicable. 
In Canada and Brazil, a physicochemical comparison is always required even when excipient composition is the same. In some jurisdictions (e.g., Australia, the EU, New Zealand, the Republic of Korea, Switzerland, the USA), a physicochemical comparison is required in cases of differences in excipient composition, whereas in other jurisdictions (Argentina, Colombia, Japan, Mexico, Singapore, South Africa, Taiwan and WHO), compliance with pharmacopoeial requirements for intravenous solutions is considered sufficient without any comparison with the comparator product. For example, in Australia, the $\mathrm{pH}$, osmolality, viscosity and buffer capacity are compared if the excipient composition is qualitatively or quantitatively modified. In the USA, the applicant will be advised to submit additional data (e.g., physicochemical data) to support the differences.

In the case of powders for reconstitution of intravenous solutions, the same requirements apply because the product is an intravenous solution at the time of administration. In the USA, this topic is not covered in the guidelines, but the same principles apply.

Intramuscular and subcutaneous solutions for injections. Argentina, Australia, Brazil, Canada, Colombia, the European Union, Mexico, New Zealand, the Republic of Korea, Singapore, South Africa, Switzerland, Taiwan, the USA and WHO accept waivers for subcutaneous and intramuscular solutions; however, in the USA in vivo PD studies may be required for certain products to demonstrate similar activities (e.g., dalteparin (37), enoxaparin (38)). In vivo studies would also be considered in the other jurisdictions for low molecular-weight heparins since they are classified as biosimilars (39). Waiver requirements are not described in current Japanese guidelines but rather waivers are assessed on a case-by-case basis.

In Australia, Brazil, Canada, Colombia, the EU, New Zealand, Singapore, the Republic of Korea, South Africa, Switzerland, the USA and WHO, a waiver is possible for oily solutions only if the same oily vehicle is used. Waiver requirements are not described in current Argentinian and Taiwanese guidelines.

As stated for intravenous injections, qualitative and quantitative differences in buffer agents, antioxidants and preservatives are acceptable in principle for all jurisdictions if the differences are scientifically justified. Argentina, Australia, Brazil, Colombia, the EU, New Zealand, Singapore, South Africa, Switzerland, Taiwan and the WHO would also accept differences in isotonic agents. Excipients such as those affecting viscosity, surfactants and complexing agents should not be changed in Australia, Canada, Colombia, the European Union, New Zealand, Singapore, the Republic of Korea, South Africa, Switzerland, Taiwan, the USA and the WHO. In contrast, Brazil and Argentina assess changes on a case-by-case basis.

In Canada and Brazil, a physicochemical comparison is always required even when excipient compositions are the same. In other jurisdictions a physicochemical comparison is required in case of differences in excipient composition (e.g., Australia, the EU, New Zealand, the Republic of Korea, South Africa, Switzerland and the USA). For example, in Australia the pH, osmolality, viscosity and buffer capacity are compared. On the contrary, compliance with pharmacopoeial requirements for intramuscular or subcutaneous solutions is considered sufficient without any comparison with the comparator product in Argentina, Colombia, Mexico, Singapore, Taiwan and WHO.

In the case of powders for reconstitution of subcutaneous or intramuscular solutions the same requirements apply because the product is a solution at the time of administration. Japan has not described this possibility in the guidelines and waivers are assessed case-by-case. In the USA this topic is not covered in the guidelines, but the same principles apply.

Intramuscular and subcutaneous suspensions for injections. For intramuscular and subcutaneous suspensions for injection, a waiver of the in vivo bioequivalence study is not acceptable in principle in any of the jurisdictions. However, in rare instances, a waiver of in vivo bioequivalence study may be acceptable, e.g., azacitidine, as specified in the product-specific guidances from the U.S. FDA (40) and Brazil (41). In vivo bioequivalence studies have also been waived for azacitidine powder for suspension for injection products by Australia, Canada, the EU and Switzerland as exceptional cases since azacitidine is not completely soluble at room temperature $\left(25^{\circ} \mathrm{C}\right)$, but rather is soluble at $37^{\circ} \mathrm{C}$. As a result, given that azacitidine dissolves soon after administration due to its drug particle size and solubility properties, it can be considered that it is released as an injectable solution if all in vitro tests are shown to be similar for the test and the reference products.

Emulsions for intravenous injection. In Australia, Canada, the EU, New Zealand, Singapore, South Africa, the Republic of Korea, Switzerland and the USA, a waiver of in vivo bioequivalence studies is possible for emulsions for intravenous injection 
(e.g., aprepitant (42), clevidipine (43) and propofol (44)), whereas a waiver is not possible in Brazil, Japan and Taiwan. In Australia, Canada, New Zealand, Singapore and South Africa the excipient composition should be qualitatively the same and quantitatively very similar while minor differences (e.g., antioxidants) have been accepted in the EU, the qualitative Republic of Korea and Switzerland. The waiver is based on physicochemical comparability of droplet size distribution of the dispersed lipid phase, viscosity / rheological properties, $\mathrm{pH}$, osmolarity, specific gravity, surface properties such as zeta potential, etc.

Waiver requirements for this type of products are not currently described in guidance documents from Argentina, Canada, Colombia and the WHO.

Micellar solutions for intravenous injection. The waiver requirements described here relate to products that are administered as micellar injections (typically formed spontaneously on dilution of a concentrate with a bulk aqueous infusion solution) and are not intended to provide a modified release of drug in vivo.

The USA does not distinguish injectable micelles as dosage form; therefore, these products are designated as injections or injectable solutions. In Australia, Canada, Colombia, the EU, New Zealand, Singapore, South Africa, the Republic of Korea, Switzerland and the WHO, a biowaiver is possible for micellar solutions for injection (e.g., docetaxel micellar solutions), whereas in Argentina and Brazil, the waiver requirements are not addressed in current guidelines and applications are assessed case-by-case. In those jurisdictions where a biowaiver is acceptable, the excipient composition should be qualitatively the same and quantitatively very similar, although minor qualitative differences in buffer agents, antioxidant and preservatives are accepted. In addition, Australia, Colombia, the EU, New Zealand, Singapore, South Africa, Switzerland and the WHO could accept qualitative changes in the co-solvents if they are not considered critical (e.g., alcohol and PEG). The waiver is based on physicochemical comparability of critical micellar concentration (CMC), micelle size distribution, solubilisation capacity (free and bound amounts) and $\mathrm{pH}$, osmolarity and viscosity.

In Japan and Taiwan waivers are not acceptable. When demonstrating in vivo bioequivalence, the excipient composition of the test product can be different from that of the reference for Taiwan but should be qualitatively and quantitatively the same for Japan except for buffer agents, antioxidants and preservatives.

\section{DISCUSSION}

The survey illustrates that the criteria employed to waive the requirement to conduct in vivo bioequivalence studies for certain types of oral and parenteral dosage forms are diverse among the members of the IPRP BEWGG. The survey results showed that as a dosage form increases in complexity, so does the risk associated with accepting biowaivers, especially in the presence of differences in composition between the generic and comparator products. This helps to explain the observation that convergence in accepting biowaivers and regulatory requirements becomes less common as a dosage form becomes more complex in composition.

In even the simplest case of an intravenous solution where an in vivo bioequivalence study can be waived in all jurisdictions, the allowable differences in excipient composition between a generic and reference are not harmonised. In the most prescriptive case, the non-medicinal ingredients in the formulations between the generic product and the reference product should be qualitatively the same and quantitatively essentially the same (within $\pm 10 \%$ absolute amount in the reference); however, differences beyond the defined criteria can be scientifically justified. In contrast, changes in preservatives, buffers, antioxidants and isotonic agents are allowed in most of the remaining jurisdictions. In the USA, the absolute amount in reference is within $\pm 5 \%$. In the most flexible case, even surfactants can be changed if they are well established for the route of administration and present in usually acceptable amounts. This change in surfactants might modify the safety profile, since not all surfactants exhibit the same tolerability profile (45).

A waiver for oral solutions has been accepted in most jurisdictions based on the fact that the drug is already dissolved and available, and it is only necessary to ensure that excipients do not affect solubility/precipitation, stability, transit time and permeability of the drug in the gastrointestinal tract. Hopefully, the present survey and scientific discussion might facilitate the development of recommendations in countries where there is no guidance (Japan) or where oily solutions cannot be waived despite having the same or similar qualitative and quantitative composition as the comparator product (Brazil and the Republic of Korea). Regarding excipients, the most prescriptive jurisdictions only accept changes in non-critical excipients of oral solutions containing BCS class I drugs, but they do not allow those changes for BCS class II, III and IV drugs. This is 
Table 2. Comparison of Biowaiver Requirements for Certain Parenteral Dosage Forms Among IPRP BEWGG Participants

\begin{tabular}{|c|c|c|c|c|c|c|c|c|c|c|c|c|c|c|c|c|}
\hline & 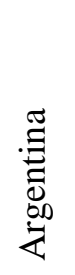 & 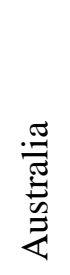 & 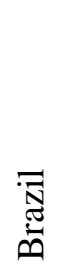 & 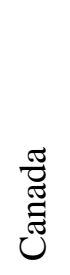 & $\begin{array}{l}\frac{\pi}{0} \\
\frac{\tilde{\Xi}}{0} \\
ن\end{array}$ & 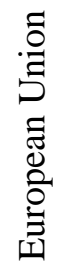 & $\underset{\tilde{\Xi}}{\tilde{\Xi}}$ & 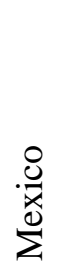 & 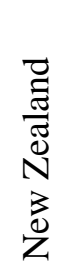 & 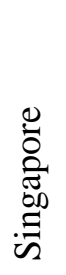 & 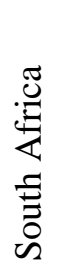 & 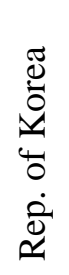 & 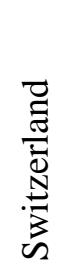 & $\underset{\Xi}{\tilde{\Xi}}$ & $\mathscr{\Omega}$ & $\stackrel{0}{\stackrel{0}{1}}$ \\
\hline \multicolumn{17}{|l|}{ Intravenous solutions } \\
\hline Accept waivers & $\mathbf{Y}$ & $\mathbf{Y}$ & $\mathbf{Y}$ & $\mathbf{Y}^{\mathbf{a}}$ & $\mathbf{Y}$ & $\mathbf{Y}$ & $\mathbf{Y}$ & $\mathbf{Y}$ & $\mathbf{Y}$ & $\mathbf{Y}$ & $\mathbf{Y}$ & $\mathbf{Y}$ & $\mathbf{Y}$ & $\mathbf{Y}$ & $\mathbf{Y}$ & $\mathbf{Y}$ \\
\hline $\begin{array}{l}\text { Accept changes in preservatives, buffer agents, } \\
\text { antioxidants }\end{array}$ & $\mathbf{Y}$ & $\mathbf{Y}^{\mathrm{e}}$ & $\mathbf{Y}$ & $\mathbf{Y}^{\mathbf{c}}$ & $\mathbf{Y}$ & $\mathbf{Y}$ & $\mathbf{Y}$ & $\mathbf{Y}$ & $\mathbf{Y}$ & $\mathbf{Y}$ & $\mathbf{Y}$ & $\mathbf{Y}$ & $\mathbf{Y}$ & $\mathbf{Y}$ & $\mathbf{Y}$ & $\mathbf{Y}$ \\
\hline Accept changes in isotonic agent & $\mathbf{Y}$ & $\mathbf{Y}$ & $\mathbf{Y}$ & $\mathbf{Y}^{\mathbf{c}}$ & $\mathbf{Y}$ & $\mathbf{Y}$ & $\mathbf{Y}$ & $\mathbf{C}$ & $\mathbf{Y}$ & $\mathbf{Y}$ & $\mathbf{Y}$ & $\mathbf{N}$ & $\mathbf{Y}$ & $\mathbf{Y}$ & $\mathbf{N}$ & $\mathbf{Y}$ \\
\hline Accept changes in surfactants & $\mathbf{C}$ & $\mathbf{N}$ & $\mathbf{Y}$ & $\mathbf{Y}^{\mathbf{c}}$ & $\mathbf{N}$ & $\mathbf{N}$ & $\mathbf{C}$ & $\mathbf{C}$ & $\mathbf{N}$ & $\mathbf{N}$ & $\mathbf{N}$ & $\mathbf{N}$ & $\mathbf{N}$ & - & $\mathbf{N}$ & $\mathbf{N}$ \\
\hline $\begin{array}{l}\text { Requires in vitro comparison with the comparator } \\
\text { even if excipients are the same }\end{array}$ & $\mathbf{N}$ & $\mathbf{N}$ & $\mathbf{Y}$ & $\mathbf{Y}$ & $\mathbf{N}$ & $\mathbf{N}$ & $\mathbf{N}$ & $\mathbf{N}$ & $\mathbf{N}$ & $\mathbf{N}$ & $\mathbf{N}$ & $\mathbf{N}$ & $\mathbf{N}$ & $\mathbf{N}$ & $\mathbf{N}$ & $\mathbf{N}$ \\
\hline $\begin{array}{l}\text { Requires in vitro comparison with the comparator if } \\
\text { differences in excipients }\end{array}$ & $\mathbf{N}$ & $\mathbf{Y}$ & $\mathbf{Y}$ & $\mathbf{Y}$ & $\mathrm{N}$ & $\mathbf{Y}$ & $\mathbf{N}$ & $\mathbf{N}$ & $\mathbf{Y}$ & $\mathbf{N}$ & $\mathbf{Y}$ & $\mathbf{Y}$ & $\mathbf{Y}$ & $\mathbf{N}$ & $\mathbf{Y}$ & $\mathbf{N}$ \\
\hline \multicolumn{17}{|l|}{ Intramuscular and subcutaneous solutions for injection } \\
\hline Accept waivers for aqueous solutions & $\mathbf{Y}$ & $\mathbf{Y}$ & $\mathbf{Y}$ & $\mathbf{Y}$ & $\mathbf{Y}$ & $\mathbf{Y}$ & $\mathbf{N}^{\mathbf{c}}$ & $\mathbf{Y}$ & $\mathbf{Y}$ & $\mathbf{Y}$ & $\mathbf{Y}$ & $\mathbf{Y}$ & $\mathbf{Y}$ & $\mathbf{Y}$ & $\mathbf{Y}$ & $\mathbf{Y}$ \\
\hline $\begin{array}{l}\text { Accept waivers for oily solutions with the } \\
\text { same oil vehicle }\end{array}$ & - & $\mathbf{Y}$ & $\mathbf{Y}$ & $\mathbf{Y}$ & $\mathbf{Y}$ & $\mathbf{Y}$ & $\mathbf{N}$ & - & $\mathbf{Y}$ & $\mathbf{Y}$ & $\mathbf{Y}$ & $\mathbf{Y}$ & $\mathbf{Y}$ & - & $\mathbf{Y}^{\mathbf{d}}$ & $\mathbf{Y}$ \\
\hline $\begin{array}{l}\text { Accept waivers for oily solutions with a } \\
\text { different oily vehicle }\end{array}$ & $\mathbf{N}$ & $\mathbf{N}$ & $\mathbf{N}$ & $\mathbf{N}$ & $\mathbf{N}$ & $\mathbf{N}$ & $\mathbf{N}$ & - & $\mathbf{N}$ & $\mathbf{N}$ & $\mathbf{N}$ & $\mathbf{N}$ & $\mathbf{N}$ & $\mathbf{N}$ & $\mathbf{N}$ & $\mathbf{N}$ \\
\hline $\begin{array}{l}\text { Accept changes in } \\
\text { preservatives, buffer agents, antioxidants }\end{array}$ & $\mathbf{Y}$ & $\mathbf{Y}^{\mathbf{e}}$ & $\mathbf{Y}$ & $\mathbf{Y}^{\mathbf{c}}$ & $\mathbf{Y}$ & $\mathbf{Y}$ & N/A & $\mathbf{Y}$ & $\mathbf{Y}$ & $\mathbf{Y}$ & $\mathbf{Y}$ & $\mathbf{Y}$ & $\mathbf{Y}$ & $\mathbf{Y}$ & $\mathbf{Y}$ & $\mathbf{Y}$ \\
\hline Accept changes in isotonic agent & $\mathbf{Y}$ & $\mathbf{Y}$ & $\mathbf{Y}$ & $\mathbf{Y}^{\mathbf{c}}$ & $\mathbf{Y}$ & $\mathbf{Y}$ & N/A & $\mathbf{Y}$ & $\mathbf{Y}$ & $\mathbf{Y}$ & $\mathbf{Y}$ & $\mathbf{N}$ & $\mathbf{Y}$ & $\mathbf{Y}$ & $\mathbf{N}$ & $\mathbf{Y}$ \\
\hline $\begin{array}{l}\text { Accept changes in all type of excipients } \\
\text { (e.g. surfactants) }\end{array}$ & $\mathbf{Y}^{\mathbf{c}}$ & $\mathbf{N}$ & $\mathbf{Y}$ & $\mathbf{Y}^{\mathbf{c}}$ & $\mathbf{N}$ & $\mathbf{N}$ & N/A & $\mathbf{Y}$ & $\mathbf{N}$ & $\mathbf{N}$ & $\mathbf{N}$ & $\mathbf{N}$ & $\mathbf{N}$ & $\mathbf{N}$ & $\mathbf{N}$ & $\mathbf{N}$ \\
\hline & & & & & & & & & & & & & & & & \\
\hline
\end{tabular}




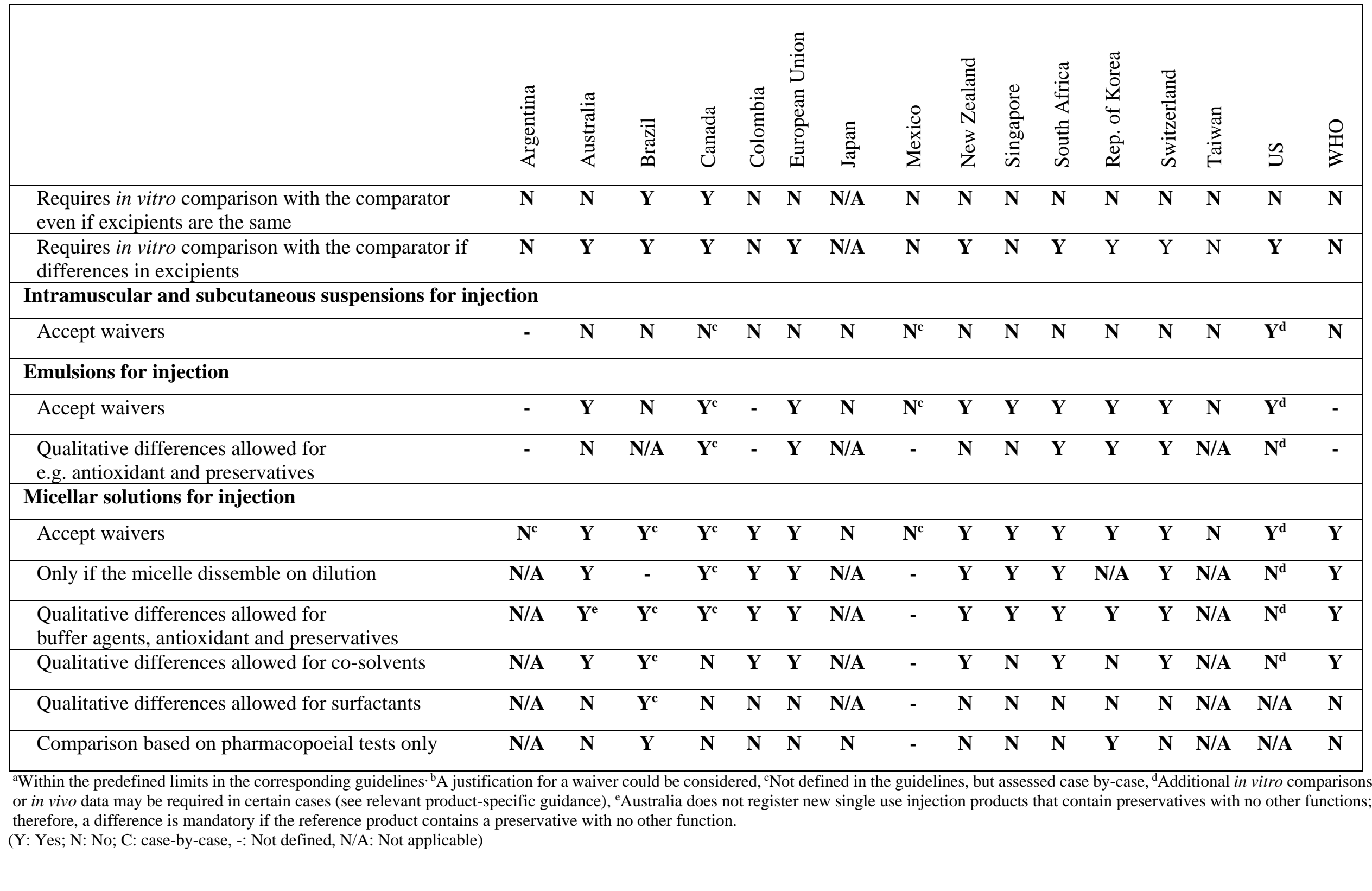


consistent with the BCS biowaivers for class III drugs where excipients should be very similar (3). For non-class I drugs, the excipients must be qualitatively the same and quantitatively similar. However, in Canada, preservatives, colorants and flavors may vary. Additionally, in Australia, Colombia, the European Union, Switzerland and the WHO, other non-functional excipients may also vary (e.g., viscosity agents, $\mathrm{pH}$ buffers and some sweeteners). In the rest of the countries, a more flexible approach is taken towards the changes in other functional excipients, like cosolvents, as long as the amount is considered 'normal' for an oral solution.

In vivo bioequivalence studies for soft gelatin capsules may be waived in some countries based on the same principle used for waivers for oily oral solutions, i.e., once the capsule shell dissolves, the capsule contents are released similar to an oily oral solution and the assumption is that the composition of the capsule shell will not affect bioavailability. However, caution should be exercised when using in vitro tests to predict in vivo behaviour. For example, a change in the composition of the capsule shell without changing the composition of the oily solution for dutasteride capsules has been shown to affect $\mathrm{C}_{\max }$ (46).

For intramuscular and subcutaneous aqueous and oily solutions for injection, almost all the jurisdictions will accept biowaivers when specified criteria are met. For example, waivers for oily solutions may be granted if the same oil vehicle is used. Japan does not have any guidance regarding the acceptability of a waiver for intramuscular and subcutaneous aqueous solutions for injection and Argentina, Japan and Taiwan lack guidance regarding waivers for oily solutions for injection. The possibility of convergence for both dosage forms may be possible when guidance documents are developed from these countries.

In contrast to oral solutions, in vivo bioequivalence studies for oral suspensions are not routinely waived with the exception of South Africa, where studies are waived based on in vitro parameters, and Argentina, Australia and Singapore, where the acceptability of a waiver is considered on a case-by-case basis. As a result, a review of the existing evidence addressing in vitro parameters that are predictive of bioequivalence seems to be necessary to facilitate regulatory convergence. It is interesting to note that some jurisdictions do not waive in vivo bioequivalence studies for systemically acting oral suspensions but may allow waivers for locally acting suspensions due to the fact that therapeutic equivalence studies using clinical, or pharmacodynamics endpoints are generally not that discriminatory when detecting potential formulation differences between different products. Furthermore, none of the jurisdictions allow waivers for intramuscular or subcutaneous suspensions for injection, except in the case of azacitidine due to its particular solubility properties.

When the formulation of a product becomes more complex, there is less commonality in the waiver requirements among the participating members. In the case of micellar solutions for intravenous injection, as illustrated by the case of docetaxel, some jurisdictions would not accept a waiver; however, other jurisdictions would allow a waiver based on in vitro data noting that the requirements for excipient similarity vary between members. Interestingly, some jurisdictions would accept qualitative differences in co-solvents, even though different storage conditions may be required to avoid precipitation. In contrast, other jurisdictions do not accept differences in excipients except for buffers, antioxidants and preservatives in order to ensure a higher degree of similarity under all conditions of use.

The requirements are even more diverse for other complex formulations such as emulsions for intravenous injections (e.g., propofol). Some jurisdictions do not accept a waiver, while others would. For those that do accept a waiver the requirements for excipient similarity vary because few jurisdictions have previously accepted qualitative differences in antioxidants. Others do not provide any guidance with respect to waivers for emulsions for intravenous injections. It is noteworthy that Brazil accepts changes in all excipients including surfactants of intravenous solutions or micellar solutions if the replacement excipients are justified and well established for that dosage form and route of administration, and used in acceptable concentrations, but does not accept waivers for emulsions even with the same qualitative and quantitative composition.

This survey shows that the criteria employed to waive in vivo bioequivalence studies for certain oral and parenteral dosages are diverse amongst the participating members of IPRP BEWGG. It also illustrates that case-by-case assessment is frequent due to the complexity of some dosage forms. Therefore, scientific evidence that justifies the national requirements should be shared in order to facilitate convergence in the future as a first step towards harmonisation and to avoid the uncertainty 
of case-by-case assessments for pharmaceutical companies.

\section{CONCLUSION}

A waiver from in vivo demonstration of bioequivalence may be applied to several orally administered and systemically acting dosage forms like oral solutions, oral suspensions and soft gelatin capsules, and some systemically-acting parenteral dosage forms like intravenous injections, subcutaneous and intramuscular injections, emulsions for injection and micellar solutions for injection. The requirements for biowaivers for the more complex dosage forms (e.g., suspensions, micellar injection) tend to be more variable among the participating members; however, as the dosage forms become less complex (e.g., oral solutions, IV injections), the requirements for biowaivers become more similar as there are less risk factors to consider that may influence the safety and efficacy of the product. The sharing of this information is a first step towards regulatory convergence in this area since, for some dosage forms, large differences between members of the BEWGG of the IPRP have been identified. The next steps should involve identifying areas that could be harmonised based on sound scientific justifications. Convergence in this area would be useful for pharmaceutical companies developing generic medicinal products for more than one of these jurisdictions.

\section{CONFLICT OF INTEREST}

This manuscript represents the personal opinions of the authors and does not necessarily represent the views or policy of their corresponding regulatory agencies.

\section{REFERENCES}

1. International Pharmaceutical Regulators Programme. http://www.iprp.global/home. Accessed on 30 December 2019.

2. van Oudtshoorn J, García-Arieta A, Mendes Lima Santos G, Crane C, Rodrigues C, Simon $\mathrm{C}$, et al. A Survey of the Regulatory Requirements for BCS-Based Biowaivers for Solid Oral Dosage Forms by Participating Regulators and Organisations of the International Generic Drug Regulators Programme. J Pharm Pharm Sci 2018; 21(1):27-37. doi: 10.18433/J3X93K.

3. ICH Harmonised Guideline Biopharmaceutics Classification System (BCS)-based biowaivers. M9. Available from:
https://database.ich.org/sites/default/files/M9 _Guideline_Step4_2019_1116.pdf.

Accessed on 30 December 2019.

4. Crane C, Santos GML, Fernandes EAF, Simon C, Tam A, Triana DG, et al. The Requirements for Additional Strength Biowaivers for Immediate Release Solid Oral Dosage Forms in International Pharmaceutical Regulators Programme Participating Regulators and Organisations: Differences and Commonalities. J Pharm Pharm Sci. 2019; 22(1):486-500. doi: 10.18433/jpps30724.

5. Therapeutic Goods Administration (Australia). Guidance 15 Biopharmaceutic Studies of the Australian Regulatory Guidelines for Prescription Medicines (April 2015). Available from:

https://www.tga.gov.au/publication/guidance15-biopharmaceutic-studies. Accessed on 30 December 2019.

6. Health Canada. Guidance for Industry: Pharmaceutical Quality of Aqueous Solutions (2005). Available from https://www.canada.ca/en/healthcanada/services/drugs-health-products/drugproducts/applications-submissions/guidancedocuments/chemical-entity-productsquality/notice-guidance-industrypharmaceutical-quality-aqueoussolutions.html. Accessed on 30 December 2019.

7. Health Canada. Policy: Submissions for Generic Parental Drugs (1990). Available from https://www.canada.ca/en/healthcanada/services/drugs-health-products/drugproducts/applicationssubmissions/policies/policy-issuessubmissions-generic-parenteral-drugs.html. Accessed on 30 December 2019.

8. Agência Nacional de Vigilância Sanitária (ANVISA) (Brazil). Law n. 9787, of $10^{\text {th }}$ February 1999. Establishes the generic drugs in Brazil (1999). Available from: http://www2.camara.leg.br/legin/fed/lei/1999/ lei-9787-10-fevereiro-1999-351613normaatualizada-pl.pdf. Accessed on 30 December 2019.

9. Agência Nacional de Vigilância Sanitária (ANVISA) (Brazil). Resolution RDC n. 37, of 3rd August 2011. Provides the guidance of biowaiver and replacement of bioequivalence studies (2011). Available from http://portal.anvisa.gov.br/documents/33880/2 568070/rdc0037_03_08_2011.pdf/13c41657e93b-4d09-99eb-377f760f3aa0. Law n. 9787, of $10^{\text {th }}$ February 1999. Establishes the generic 
drugs in Brazil (1999). Accessed on 30 December 2019.

10. Comisión Federal para la Protección contra Riesgos Sanitarios (COFEPRIS). Article 2, fraction XIV Bis, of the Reglamento de Insumos Para la Salud, (Health Products Regulation). Available from: https://sidof.segob.gob.mx/notas/5314833. Accessed on 30 December 2019.

11. Health Sciences Authority (Singapore). Appendix 10 Product Interchangeability and Biowaiver Request for Chemical Generic Applications, Guidance on Medicinal Product Registration in Singapore (April 2018). Available from: https://www.hsa.gov.sg/docs/defaultsource/hprg-tpb/generic-drug/appendix10_product-interchangeability-and-biowaiverrequest-for-chemical-generic-drugapplications.pdf. Accessed on 30 December 2019.

12. Instituto Nacional de Vigilancia de Medicamentos y Alimentos (Colombia). Resolución 1124 de 2016. Por la cual se establece la Guía que contiene los criterios y requisitos para el estudio de Biodisponibilidad y Bioequivalencia de medicamentos, se define el listado de los que deben presentarlos y se establecen las condiciones de las Instituciones que los realicen (April 2016). Available from: https://www.minsalud.gov.co/sites/rid/Lists/B ibliotecaDigital/RIDE/DE/DIJ/resolucion1124-de-2016.pdf. Accessed on 30 December 2019.

13. South African Health Products Regulatory Authority. Quality and bioequivalence guideline

https://www.mm3admin.co.za/documents/doc manager/editor/9400/UserFiles/Guideline $\% 20$ Trench/2.02_quality\%20and\%20bioequivalen ce\%20guideline_jul19_v7.pdf. Accessed on 30 December 2019.

14. South African Health Products Regulatory Authority. Dissolution (June 2015). https://sahpra.org.za/wpcontent/uploads/2020/01/059932092.07_Diss olution_Jun15_v5_showing_changes.pdf. Accessed on 1 September 2019.

15. Medsafe (New Zealand). Part 6: Bioequivalence of medicines, Guideline on the Regulation of Therapeutic Products in New Zealand (June 2015). Available from: http://www.medsafe.govt.nz/regulatory/Guide line/GRTPNZ/bioequivalence-of-

medicines.pdf. Accessed on 30 December 2019.

16. Ministry of Health, Labour and Welfare
(MHLW). Guideline for Bioequivalence Studies of Generic Products, Japan (February 2012). Available from: http://www.nihs.go.jp/drug/beguide(e)/Generic/GL-E_120229_BE.pdf. Accessed on 30 December 2019.

17. Ministry of Food and Drug Safety (The Republic of Korea). Standard on Pharmaceutical Equivalence Study; Notification No. 2019-141 (Dec. 30, 2019, Amended)].

http://www.law.go.kr/\%ED\%96\%89\%EC\%A 0\%95\%ЕА\%В7\%9С\%ЕC\%В9\%99/\%ЕC\%9 D\%98\%EC\%95\%BD\%ED\%92\%88\%EB\%8F $\% 99 \%$ ЕВ $\% 93 \%$ В1\%ЕC\%84\%В1\%ЕC\%8B $\% 9 \mathrm{C} \% \mathrm{ED} \% 97 \% 98 \% \mathrm{EA} \% \mathrm{~B} 8 \% \mathrm{~B} 0 \% \mathrm{EC} \% \mathrm{~A} 4$ $\% 80$. Accessed on 29 January 2020.

18. Swissmedic (Switzerland): HD-Guidance document Authorisation of human medicinal product with known active pharmaceutical ingredient HMV4 (February 2019). Available from:

https://www.swissmedic.ch/dam/swissmedic/e n/dokumente/zulassung/zl_hmv_iv/zl101_00_ 007d_wlanleitungzulassungvonhumanarzneim ittelnmitbekann.pdf.download.pdf/ZL101_00_ 007e_WL\%20Guidance\%20document $\% 20 \mathrm{Au}$ thorisation $\% 20$ of $\% 20$ human $\% 20$ medcine $\% 20$ with\%20known\%20active\%20pharmaceutical $\% 20$ ingredient. Accessed on 30 December 2019.

19. Taiwan Food and Drug Administration (Taiwan). Regulation of Bioavailability and Bioequivalence Studies, Ministry of Health and Welfare, Taiwan (March 2015). Available from:

https://law.moj.gov.tw/ENG/LawClass/LawAl 1.aspx ?pcode $=$ L0030065. Accessed on 30 December 2019.

20. World Health Organisation (WHO). Annex 6. Multisource (generic) pharmaceutical products: guidelines on registration requirements to establish interchangeability. WHO Technical Report Series, No. 1003, 2017. Available from: https://www.who.int/medicines/areas/quality_ safety/quality_assurance/expert_committee/W HO_TRS_1003_full-version.pdf?ua=1. Accessed on 1 September 2020.

21. Administración Nacional de Medicamentos, Alimentos y Tecnología Médica (ANMAT). Disposición $\mathrm{N}^{\circ}$ 3185, 25 June 1999. Recomendaciones técnicas contenidas en el documento "Cronograma para exigencias de estudios de equivalencia entre medicamentos de riesgo sanitario significativo". Available from: 
http://www.anmat.gov.ar/webanmat/Legislaci on/Medicamentos/Disposicion_ANMAT_318 5-1999.pdf. Accessed on 30 December 2019.

22. Administración Nacional de Medicamentos, Alimentos y Tecnología Médica (ANMAT). Disposición No 25814, 18 June 2002. "Formas farmacéuticas y/o vías de administración que no requerirán la realización de estudios de equivalencia". Available from: http://www.anmat.gov.ar/webanmat/Legislaci on/Medicamentos/Disposicion_ANMAT_281 4-2002.pdf. Accessed on 30 December 2019.

23. Committee for Medicinal Products for Human Use (CHMP). Guideline on the investigation of bioequivalence. Ref. Doc.: CPMP/EWP/QWP/1401/98 Rev. 1/ Corr **. London, 20 January 2010. Available from: https://www.ema.europa.eu/en/documents/sci entific-guideline/guideline-investigationbioequivalence-rev1_en.pdf. Accessed on 30 December 2019.

24. Clinical pharmacology and pharmacokinetics: questions and answers. 6.3 Clarification on how to apply the reference made in Appendix II of the Guideline on the investigation of bioequivalence (CPMP/EWP/QWP/1401/98 Rev.1/Corr**), when waiving in vivo studies for oral solutions. December 2016. Available from:

http://www.ema.europa.eu/ema/index.jsp?cur l=pages/regulation/q_and_a/q_and_a_detail_ 000179.jsp\&mid=WC0b01 ac0580aff2ec\#sec tion6. Accessed on 30 December 2019.

25. Inactive Ingredient Search for Approved Drug Products. Available from: https://www.accessdata.fda.gov/scripts/cder/ii g/index.cfm. Accessed on 30 December 2019.

26. Center for Drug Evaluation and Research (CDER). Guidance for Industry. Immediate Release Solid Oral Dosage Forms. Scale-Up and Postapproval Changes: Chemistry, Manufacturing, and Controls, In Vitro Dissolution Testing, and In Vivo Bioequivalence Documentation. November 1995. Available from: https://www.fda.gov/media/70949/download. Accessed on 16 May 2020.

27. Committee for Medicinal Products for Human Use (CHMP). Equivalence studies for the demonstration of therapeutic equivalence for locally applied, locally acting products in the gastrointestinal tract. CPMP/EWP/239/95 Rev. 1, Corr.1*. 18 October 2018. Available from:

https://www.ema.europa.eu/en/documents/sci entific-guideline/guideline-equivalence-

studies-demonstration-therapeutic- equivalence-locally-applied-locally-

acting_en.pdf. Accessed on 30 December 2019.

28. Draft Guidance on Sevelamer Carbonate. Suspension, oral. https://www.accessdata.fda.gov/drugsatfda_d ocs/psg/Sevelamer_carbonate_oralsusp_0223 18_RV12-14.pdf. Accessed on 30 December 2019.

29. Draft Guidance on Sevelamer Carbonate. Tablet, oral. https://www.accessdata.fda.gov/drugsatfda_d ocs/psg/Sevelamer\%20carbonate_oral\%20tab let_022127_RV09-15.pdf. Accessed on 30 December 2019.

30. Draft Guidance on Sevelamer Hydrochloride. Tablet, oral. https://www.accessdata.fda.gov/drugsatfda_d ocs/psg/Sevelamer_HCl_tab_021179_RV1214.pdf. Accessed on 30 December 2019.

31. Draft Guidance on Colesevelam Hydrochloride. Power for suspension, oral. https://www.accessdata.fda.gov/drugsatfda_d ocs/psg/Colesevelam\%20hydrochloride_oral \%20suspension_022362_RV01-16.pdf.

Accessed on 30 December 2019.

32. Draft Guidance on Colesevelam Hydrochloride. Tablet, oral. https://www.accessdata.fda.gov/drugsatfda_d ocs/psg/Colesevelam\%20hydrochloride_oral \%20tablet_021176_RV09-15.pdf. Accessed on 30 December 2019.

33. Draft Guidance on Cholestyramine. Powder, oral.

https://www.accessdata.fda.gov/drugsatfda_d ocs/psg/Cholestyramine_oral\%20powder_74 557\%20and\%2074558_RV06-15.pdf.

Accessed on 30 December 2019.

34. Draft Guidance on Omega-3-Acid Ethyl Esters. Capsule, oral. https://www.accessdata.fda.gov/drugsatfda_d ocs/psg/Omega-

3\%20Acid\%20Ethyl\%20Esters_oral\%20caps ule_RLD\%20021654_RV12-16.pdf.

Accessed on 30 December 2019.

35. Draft Guidance on Progesterone. Capsule, oral. Available from: https://www.accessdata.fda.gov/drugsatfda_d ocs/psg/Progesterone_caps_19781_RC0211.pdf. Accessed on 30 December 2019.

36. Clinical pharmacology and pharmacokinetics: questions and answers. 4.4 Bioequivalence studies for generic application of omega 3 fatty acid ethylesters in a soft gelatine capsule. October 2013. Available from: https://www.ema.europa.eu/en/humanregulatory/research-development/scientific- 
guidelines/clinical-pharmacology-

pharmacokinetics/clinical-pharmacology-

pharmacokinetics-questions-answers.

Accessed on 30 December 2019.

37. Draft Guidance on Dalteparin Sodium. Injectable/Subcutaneous. Available from: https://www.accessdata.fda.gov/drugsatfda_d ocs/psg/Dalteparin_Inj_20287_RC09-12.pdf. Accessed on 30 December 2019.

38. Draft Guidance on Enoxaparin Sodium. Injectable/Subcutaneous. Available from: https://www.accessdata.fda.gov/drugsatfda_d ocs/psg/Enoxaparin_Inj_20164_RC1011.pdf. Accessed on 30 December 2019.

39. Committee for Medicinal products for Human (CHMP). Guideline on non-clinical and clinical development of similar biological medicinal products containing lowmolecular-weight-heparins.

EMEA/CHMP/BMWP/118264/2007 Rev. 1. 10 November 2016. Available from: https://www.ema.europa.eu/en/documents/sci entific-guideline/guideline-non-clinicalclinical-development-similar-biologicalmedicinal-products-containing-low_en.pdf. Accessed on 30 December 2019.

40. Draft Guidance on Azacitidine. Powder; IV (Infusion), Subcutaneous. Available from: https://www.accessdata.fda.gov/drugsatfda_d ocs/psg/Azacitidine_subcutaneous $\% 20$ and $\%$ 20IV\%20infusion\%20powder_NDA\%20050 794_RV04-17.pdf. Accessed on 30 December 2019.

41. Estudos comparativos com Azacitidina. Available from: http://portal.anvisa.gov.br/documents/33836/3 275182/Estudos+comparativos+com+azacitidi na.pdf/500e9ae5-4a8c-4205-94d2eed218a256bc. Accessed on 30 December 2019.

42. Draft Guidance on Aprepitant. Intravenous; Emulsion. Available from: https://www.accessdata.fda.gov/drugsatfda_d ocs/psg/PSG_209296.pdf. Accessed on 1 September 2020.

43. Draft Guidance on Clevidipine. Intravenous; Emulsion. Available from: https://www.accessdata.fda.gov/drugsatfda_d ocs/psg/PSG_022156.pdf . Accessed on 1 September 2020.

44. Draft Guidance on Propofol. Injectable; injection. Available from: https://www.accessdata.fda.gov/drugsatfda_d ocs/psg/Propofol_injectable\%20injection_RL D\%2019627_RC06-16.pdf. Accessed on 30 December 2019.
45. van Zuylen, L., Verweij, J. \& Sparreboom, A. Role of Formulation Vehicles in Taxane Pharmacology. Invest New Drugs (2001) 19: 125. doi.org/10.1023/A:101061863273

46. GSK Study ID: 204646. Available from: https://s3.amazonaws.com/ctr-gsk7381/204646/8272588b-47e1-4a6b-957168141e74b238/6bfc2884-472b-43e9-9b3a209f9a7d7c49/gsk-204646-clinical-studyresult-summary-v1.pdf. Accessed on 30 December 2019. 